\title{
Type 1 diabetes and cardiovascular disease
}

\author{
Oliver Schnell ${ }^{1 *}$, Francesco Cappuccio ${ }^{2}$, Stefano Genovese ${ }^{3}$, Eberhard Standl ${ }^{1}$, Paul Valensi ${ }^{4}$ and Antonio Ceriello ${ }^{5}$
}

\begin{abstract}
The presence of cardiovascular disease (CVD) in Type 1 diabetes largely impairs life expectancy. Hyperglycemia leading to an increase in oxidative stress is considered to be the key pathophysiological factor of both micro- and macrovascular complications. In Type 1 diabetes, the presence of coronary calcifications is also related to coronary artery disease. Cardiac autonomic neuropathy, which significantly impairs myocardial function and blood flow, also enhances cardiac abnormalities. Also hypoglycemic episodes are considered to adversely influence cardiac performance. Intensive insulin therapy has been demonstrated to reduce the occurrence and progression of both micro- and macrovascular complications. This has been evidenced by the Diabetes Control and Complications Trial (DCCT) / Epidemiology of Diabetes Interventions and Complications (EDIC) study. The concept of a metabolic memory emerged based on the results of the study, which established that intensified insulin therapy is the standard of treatment of Type 1 diabetes. Future therapies may also include glucagon-like peptide (GLP)-based treatment therapies. Pilot studies with GLP-1-analogues have been shown to reduce insulin requirements.
\end{abstract}

Keywords: Type 1 diabetes, Cardiovascular disease

\section{Introduction}

Over the past 40 years, a reduction in the mortality due to cardiovascular $(\mathrm{CV})$ disease and coronary heart disease (CHD) by about $70 \%$ both in diabetic and non-diabetic patients has been observed [1]. The cause is presumed to be a substantial progress in $\mathrm{CV}$ risk factor management and interventional cardiology [1]. Furthermore, in patients with type 1 diabetes, a decrease in mortality and a remarkable improvement in life expectancy occurred during the past decades $[2,3]$. The comparison of two subcohorts of the Pittsburgh Epidemiology of Diabetes Complications study based on the period of diabetes diagnosis (1950-1964 vs. 1965-1980) found an increase in life expectancy by approximately 14 years [3]. Nevertheless, the overall risk of CVD for people with type 1 diabetes compared to people without diabetes is increased two- to threefold in men, and three- to fivefold in women. A significant increase in CVD mortality related to increasing HbA1c levels has been reported in type 1 diabetes [4].

The aim of this paper is to present an overview on epidemiologic and pathophysiologic aspects of the relation between type 1 diabetes and CVD. In addition, the

\footnotetext{
* Correspondence: Oliver.Schnell@|rz.uni-muenchen.de

${ }^{1}$ Forschergruppe Diabetes e.V., Helmholtz Center Munich, Ingolstaedter Landstrasse 1,85764 Munich-Neuherberg, Germany

Full list of author information is available at the end of the article
}

management of risk factors, both with view on diagnostic and therapeutic approaches, is addressed.

\section{Epidemiology}

In the EURODIAB IDDM Complications Study, including more than 3.200 patients with type 1 diabetes from 16 European countries, the prevalence of CVD was reported to be $9 \%$ in men and $10 \%$ in women, respectively [5]. Related to an increase in duration of diabetes and age, an increase from $6 \%$ in the age group of $15-29$ years to $25 \%$ in the age group of 45-59 years, has been observed [5].

In type 1 diabetes as compared to type 2 diabetes, the relationship of hyperglycemia with microangiopathy as well as macroangiopathy seems to be more significant $[6,7]$. According to the results of a large Finnish database, CVD mortality in patients with type 1 diabetes aged from 45-64 years at baseline increases by about $50 \%$ with every $1 \%$ increase of glycated haemoglobin (HbA1c) [6].

In a population-based cohort of 879 individuals with type 1 diabetes from Wisconsin, hyperglycemia was associated with all-cause and cardiovascular mortality [8]. At baseline examination (1980-1982), patients were free of cardiovascular disease and end-stage renal disease. The patients were followed up until December 2001. The multivariable relative risks comparing the highest quartile of

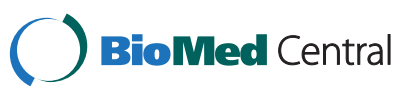


HbA1c ( $\geq 12.1 \%)$ with the lowest quartile $(\leq 9.4 \%)$ were 2.42 (95\% CI: 1.54, 3.82; p-trend $=0.0006)$ for all-cause mortality and 3.28 (95\% CI: 1.77, 6.08; p-trend < 0.0001) for cardiovascular mortality [8]. This association was present among both sexes, and independent of duration of diabetes, smoking, hypertension, and proteinuria. The relation persisted in subgroup analyses by categories of diabetes duration, smoking, body mass index, proteinuria, and retinopathy [8].

In a Japanese study, which included type 1 diabetes, who were diagnosed at an age of $<18$ years between 1965 and 1979, CVD was identified as the leading cause of death in diabetes of more than 20 years of duration [9].

Recently, the long-term clinical outcomes and survival in patients with both young-onset type 2 and type 1 diabetes with a similar age of diagnosis were evaluated [10]. As compared with type 1 , type 2 demonstrated to present to be associated with a more lethal phenotype and a higher mortality. Also diabetic complications were detected more frequently [10].

\section{Pathophysiology / Etiology}

Long-term hyperglycemia, both in type 1 and type 2 diabetes, leads to microvascular and macrovascular complications [11]. Microvascular damage affects particularly the retina, kidneys, both the autonomic and peripheral nervous system, while the heart, brain, lower limbs, are affected by both micro- and macrovascular disorders [11].

\section{Oxidative stress}

Hyperglycemia-induced overproduction of superoxide by the mitochondrial electron-transport chain is supposed to be the key element in the activation of all other pathways involved in the pathogenesis of diabetic complications (Figure 1) [12,13]. These include an increase in polyol pathway flux and advanced glycation end product formation, an activation of protein kinase $\mathrm{C}$, and an increase in hexosamine pathway flux. Superoxide overproduction is accompanied by increased nitric oxide generation, due to an endothelial nitric oxide synthase (NOS) and inducible NOS uncoupled state. Thus, the formation of the strong oxidant peroxynitrite is favoured, which in turn is damaging deoxyribonucleic acid (DNA) $[12,13]$.

Due to this DNA damage, a rapid activation of poly (adenosine diphosphate [ADP]-ribose) polymerase occurs, in turn depleting the intracellular concentration of its substrate nicotinamide adenine dinucleotide $\left(\mathrm{NAD}^{+}\right)$, and slowing the rate of glycolysis, electron transport, and adenosintriphosphate (ATP) formation. In addition, the ADP-ribosylation of the glyceraldehyde 3-phosphate dehydrogenase (GAPDH) is stimulated. These processes result in acute endothelial dysfunction, which is contributing to the genesis of diabetic complications $[12,13]$.

\section{Inflammation}

Also an increase in inflammatory cytokines is supposed to contribute to plaque instability in patients with diabetes [14]. Several inflammatory markers including C-reactive protein, interleukin (IL)-6, IL-8, tumor necrosis factor (TNF)- $\alpha$, and endothelin-1 are increased during hypoglycemia. The accumulation of inflammatory cytokines is assumed to cause endothelial injury and abnormalities in coagulation, resulting in increased risk for CV events [14].

\section{Hypercoagulability}

The coagulation system is altered due to changes in clotting factor levels and/or activity. Plasma levels of procoagulant factors are increased while fibrinolytic capacity is decreased [15]. Hyperinsulinemia results in increased hepatic synthesis of prothrombotic factors such as fibrinogen and plasminogen activator inhibitor (PAI)-1, thereby creating a thrombotic milieu. Furthermore, diabetes causes quantitative modifications in clotting factors, including glycation and oxidation which also increase thrombosis risk [15].

\section{Autonomic neuropathy}

Cardiac autonomic neuropathy (CAN) detected by standard tests is a common complication of type 1 diabetes. CAN prevalence is around $20 \%$ and increases with age and diabetes duration with an about $2 \%$ annual increase [16]. Poor glycemic control is a strong risk factor for CAN as supported by the EURODIAB study [17]. In the DCCT study intensive insulin treatment reduced the incidence of CAN by $53 \%$ compared to conventional therapy [18]. In the EDIC study, at the 13th-14th year after DCCT closeout, the prevalence and incidence of CAN remained significantly lower in the former intensive than in the former conventional group [19].

Several studies showed the predictive value of CAN on mortality [16] and that CAN is an independent predictor of mortality. CAN was reported to be a predictor of $\mathrm{CV}$ morbidity and mortality in type 1 diabetes [20]. Various $\mathrm{CV}$ disorders associated with CAN and resulting from vagal impairment and sympathetic predominance were shown mostly in type 2 diabetes and may account for the poor prognosis related to CAN [16]. Such disorders have been far less studied in patients with type 1 diabetes. In a study on patients with type 1 and type 2 diabetes, the prevalence of hypertension was shown to increase with CAN severity (from $3.6 \%$ in the patients without CAN to $36.4 \%$ in those with severe CAN), and CAN was an independent risk factor for hypertension [21]. This association suggests that vagosympathetic imbalance with a relative sympathetic overdrive may be involved in hypertension. In the Pittsburgh EDC study, CAN was associated with increased arterial stiffness 18 years later [22]. There is 


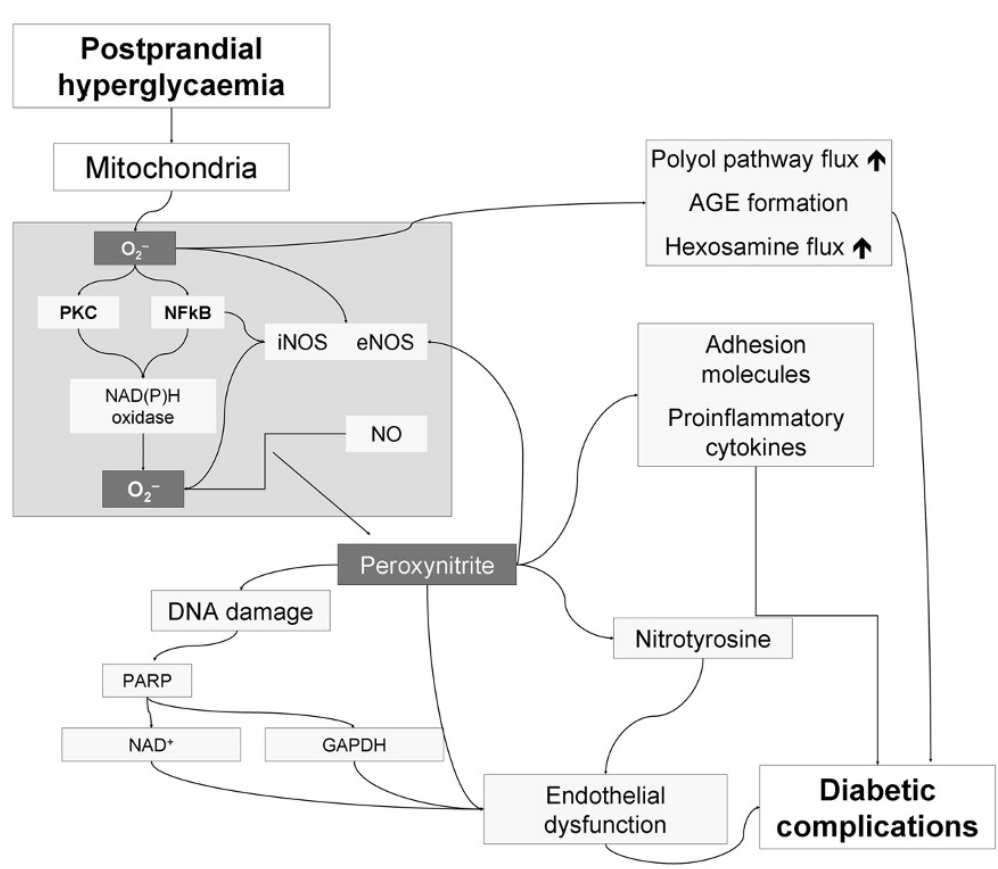

Figure 1 Pathogenesis of diabetic complications: Hyperglycemia-induced overproduction of superoxide by the mitochondrial electron-transport chain is supposed to be the key element. By activation of different pathways, the formation of the strong oxidant peroxynitrite is favoured, which in turn is damaging DNA. Through several intermediate steps, acute endothelial dysfunction, contributing to the genesis of diabetic complications, is triggered [13].

also strong evidence, based on studies in patients with type 1 or type 2 diabetes, that QT interval prolongation is an independent predictor of mortality, for all-cause and for cardiovascular deaths [16].

The balance of the activity of the autonomic nervous system is considered to play a key role for the performance of the diabetic heart [23]. Advanced single-photon emission computed tomography (SPECT) and positron emission tomography (PET) allow to directly and sensitively assess cardiac sympathetic innervation [24-29], coronary blood flow $[30,31]$ and myocardial metabolism [32,33]. In longterm type 1 diabetes, myocardial blood flow response to sympathetic stimulation is significantly impaired.

Scintigraphically, cardiac sympathetic dysinnervation was identified in $77 \%$ of newly diagnosed metabolically stabilized type 1 diabetic patients [27]. The pattern of cardiac sympathetic dysinnervation of newly diagnosed type 1 diabetic patients is heterogeneous with a predominant affection of the posterior myocardial region [25,27]. More recent publications, however, emphasize that neither impairment of metabolic control nor the presence of $\mathrm{CV}$ denervation may be a prerequisite for the development of impaired vasodilatory reserve. Diastolic dysfunction occurring early in the course of type 1 diabetes has been reported to be associated with abnormal cardiac sympathetic function as assessed by cardiac sympathetic imaging [34,35].

Neuronal abnormalities are reported to progress with duration of diabetes [36]. In parallel, defects of cardiac sympathetic innervation are more enhanced in long-term than in newly diagnosed type 1 diabetic patients [25,27]. In patients with a long diabetes history, heterogeneity of cardiac sympathetic dysinnervation, characterized by a more advanced affection of the posterior myocardium in comparison to the anterior, lateral and septal myocardium has been observed [25]. In studies on small groups of patients with type 1 diabetes, frequent sympathetic dysinnervation and a predominance in the posterior myocardial region [37], and proximal sympathetic hyperinnervation of the heart [38] has been observed with PET.

Immunological factors against sympathetic ganglia have been reported to be associated with cardiac sympathetic dysfunction [39-45]. Autoantibodies against sympathetic ganglia have been found in $20-35 \%$ of type 1 diabetic patients $[39,41,42]$. The presence of autoantibodies against sympathetic ganglia has been shown to be associated with scintigraphically assessed cardiac sympathetic dysfunction $[39,41]$ and electrocardiogram (ECG)-based abnormalities of heart rate variation [41]. Autoantibodies against sympathetic ganglia seem to be rather specific for cardioneuropathy of type 1 diabetic patients [41].

\section{Hypoglycemia}

Additional hemodynamic changes have been reported to be associated with hypoglycemia [46]. An increase in heart rate and peripheral systolic blood pressure as well as a reduction in central blood pressure and peripheral arterial resistance 
(causing a widening of pulse pressure) has been described. Furthermore, an increase in myocardial contractility, stroke volume, and cardiac output has been observed [47]. In healthy people, arteries have been reported to become more elastic during hypoglycemia with a decline in wall stiffness [46]. In people with a longer history of type 1 diabetes, however, due to an enhanced arterial wall stiffness, hypoglycemia is followed by a less pronounced fall in central arterial pressure $[46,48]$. As a consequence, temporarily a markedly increase in the workload of the heart has to be assumed [46].

In the ECG, hypoglycemia has been found to elicit ST wave changes with lengthening of the QT interval [49] and cardiac repolarization [50]. Thereby, the risk for arrhythmia is assumed to be increased [46]. Related to hypoglycemia, various abnormal heart rhythms, including ventricular tachycardia and atrial fibrillation, have been observed. In conclusion, hypoglycemia has been found to potentially cause abnormal electrical activity in the heart and is assumed to can provoke sudden death [46].

An association between hypoglycemia and sudden death has been deteced by different investigators [51-56]. In line with the hypothesis an autopsy study demonstrated, that sudden unexpected deaths were four times more frequent in type 1 diabetic patients than in nondiabetic people [56].

\section{CV risk}

\section{Risk factors for microvascular complications}

The risk of microvascular complications is influenced by several factors, such as puberty, blood pressure, dyslipidemia, gender, diabetes duration, smoking and lifestyle [57-59]. Poor metabolic control was identified as an important factor contributing to microvascular complications $[60,61]$. In addition, familial risk factors related to all microvascular complications of type 1 diabetes have been reported [62]. A study performed in type 1 diabetic patients (onset age $<30$ years) among 6,707 families revealed a significantly increased risk of retinopathy (odds ratio 9.9; CI 5.6-17.7, $\mathrm{P}<0.001$ ), nephropathy (6.2; CI 2.9-13.2, $\mathrm{P}<0.001$ ) and neuropathy (2.2; CI 1.0-5.2; $\mathrm{P}<0.05)$ in type 1 diabetic siblings of patients diagnosed with those complications [62].

In an analysis of 572 type 1 diabetic participants of the Pittsburgh EDC Study (mean follow-up: 15 years), baseline HbA1c was an independent risk factor for fatal CAD, along with duration of diabetes and albuminuria [63]. Baseline lower insulin dose, however, was strongly predictive for non-fatal CAD, as was lower renal function, higher diastolic blood pressure, and lipids [63].

In patients with diabetes onset at age 5-14 years, a higher risk for complications (retinopathy, nephropathy, and neuropathy) has been found as compared to patients diagnosed either at a very young age or after puberty [62]. In adolescents with type 1 diabetes, an elevated blood pressure or BMI [64-66], dyslipidemia and smoking [67-69] are associated with an elevated risk of incipient nephropathy, early retinopathy and peripheral neuropathy.

With the onset of diabetic nephropathy, a dramatic increase in the risk for CAD has to be assumed. After 20 years with diabetes, up to $29 \%$ of patients with childhoodonset of type 1 diabetes and nephropathy will have CAD compared to only $2-3 \%$ in similar patients without nephropathy [70]. In addition to traditional cardiovascular disease risk factors, elevated mean HbA1c and macroalbuminuria are significantly associated with alterations in left ventricular structure and function evaluated by cardiac magnetic resonance imaging (MRI) [71].

In observational studies the relationship between blood pressure and the progression of chronic kidney disease (CKD) and incident end-stage renal disease (ESRD) is direct and progressive in diabetes [72]. However, most of the evidence is in type 2 diabetes, high blood pressure is a common feature also of type 1 diabetes and an increase in blood pressure in type 1 diabetes increases the risk of nephropathy $[73,74]$. Masked hypertension is not infrequent [72]. In people with type 1 diabetes an increase in systolic blood pressure, particularly at night, precedes the development of microalbiminuria [75]. It has been argued that, unlike in type 2 diabetes, in people with type 1 diabetes hypertension develops often after the establishment of microalbuminuria. Hence, monitoring blood pressure throughout the 24 hours in type 1 diabetes may be a useful diagnostic procedure.

In the DCCT/EDIC study, during a 15.8-year median follow-up, 630 of 1441 participants developed hypertension [76]. Intensive therapy during the DCCT reduced the risk of incident hypertension by $24 \%$ during EDIC study followup. A higher HbA1c level, measured at baseline or during follow-up, was associated with increased risk for incident hypertension. Older age, male sex, family history of hypertension, greater baseline body mass index, weight gain, and greater albumin excretion rate were independently associated with increased risk of hypertension. These data show that hyperglycemia is a risk factor for incident hypertension in type 1 diabetes and that intensive insulin therapy reduces the long-term risk of developing hypertension.

In a recently published Brazilian study on approximately 1,300 patients with type 1 diabetes, however, body size and blood pressure were not correlated to lipid levels and glycemic control [77]. Correlation of serum lipids with HbA1c was shown to be heterogeneous across the spectrum of glycemic control. Several pathophysiological factors were suggested based on the HbA1c-level. These results, therefore, do not support a unified explanation for cardiovascular risk in type 1 diabetes [77].

\section{Cardiovascular risk markers}

As demonstrated in 144 participants of the Pittsburgh EDC Study, pulse wave analysis (PWA) may contribute 
to assessment of $\mathrm{CV}$ risk in patients with type 1 diabetes [78]. Arterial stiffness index, augmentation index, augmentation pressure, subendocardial viability ratio (serving as an estimate of myocardial perfusion), electron beam computed tomography-measured coronary artery calcification $(\mathrm{CAC})$ and ankle-brachial index $(\mathrm{ABI})$ were determined. In the analysis of cross-sectional associations, greater augmentation pressure was independently associated with prevalent $\mathrm{CAD}$ and estimated myocardial perfusion with low ABI $(<0.90)$ [78].

In the DCCT/EDIC study the stiffness/distensibility of the ascending thoracic aorta was measured with magnetic resonance imaging in 879 patients [79]. After adjusting for gender and cohort, aortic distensibility was lower with increasing age, mean systolic blood pressure, LDL cholesterol, and HbA1c measured over an average of 22 years. Patients with macroalbuminuria had $25 \%$ lower aortic distensibility compared with those without, and lower distensibility also was associated with greater ratio of left ventricular mass to volume. This data stand in favour of strong adverse effects of hypertension, chronic hyperglycemia and macroalbuminuria on aortic stiffness in type 1 diabetes.

After 15 years additional follow-up in EDIC, left ventricular indices were measured by cardiac magnetic resonance imaging in 1017 of the 1371 members of the DCCT cohort [80]. Mean DCCT/EDIC HbA1c over time was associated with end diastolic volume, stroke volume, cardiac output, left ventricular mass, LV mass/EDV, and aortic distensibility. These associations persisted after adjustment for CVD risk factors. Thus, cardiac function and remodeling in the EDIC cohort was associated with prior glycemic exposure (glycemic memory).

As part of the EDIC study, 1229 patients with type 1 diabetes underwent ultrasonography of the internal and common carotid arteries in 1994-1996 and again in 1998-2000 [81]. At year 1 of the EDIC study, the carotid intima-media thickness (IMT) was similar to that in an age- and sex-matched nondiabetic population. After six years, the IMT was significantly greater in the diabetic patients than in the controls. The mean IMT progression was significantly less in the group that had received intensive therapy during the DCCT than in the group that had received conventional therapy after adjustment for other risk factors. IMT progression was associated with age, and the EDIC base-line systolic blood pressure, smoking, the LDL/HDL ratio, and urinary albumin excretion rate and with the mean $\mathrm{HbAlc}$ value during the mean duration of the DCCT. Thus, intensive therapy during the DCCT resulted in decreased progression of IMT six years after the end of the trial, which again stands in favour of the effect of glycemic memory.

As found by the 10-year follow-up examination of the Pittsburgh Epidemiology of Diabetes Complications (EDC) Study cohort, CAC is related to clinical coronary artery disease (CAD) independent of other risk factors [82]. This association, however, was stronger in men than in women [82]. In a cohort of patients with type 1 diabetes (aged 22-50 years), progression of CAC, as identified by electron beam computed tomography (EBCT), was strongly associated with suboptimal glycemic control (HbA1c > 7.5\%) [83].

In a study assessing $\mathrm{CAC}$ with multislice spiral computed tomography (MSCT), nearly one third of asymptomatic long-term type 1 diabetic patients presented with coronary calcifications [84]. In patients with coronary calcifications, both cardiac autonomic neuropathy and retinopathy were detected more frequently than in those without ( $64 \%$ vs. $29 \%, \mathrm{p}<0.02 ; 59 \%$ vs. $31 \%$; $\mathrm{p}<0.02$ ). Additionally, duration of diabetes was longer in patients with than without coronary calcification [84].

In a small cohort of adolescent, non-obese type 1 diabetic patients, an increased carotid intima-media thickness was found to be associated with insulin resistance. A causal relationship, however, cannot be concluded [85]. According to a prospective longitudinal study in children and adolescents with type 1 diabetes, systolic blood pressure and body mass index are related to carotid intima-media thickness increment. Control of these risk factors is supposed to contribute to prevention of carotid intima-media thickness progression [86].

In patients with long-term duration type 1 diabetes, sexual dysfunction was demonstrated to be independently associated with CVD and to potentially predict CVD [87].

Results on the predictive value of plasminogen activator inhibitor-1 (PAI-1) are inconsistent. One study found PAI-1 levels to be independently related to CAC in younger ( $<45$ years) patients with type 1 diabetes [88]. According to another analysis, neither PAI-1 nor tPAPAI-1 is an independent predictor of CAD [89].

\section{Diagnosis / Screening}

In type 1 diabetes, hypertension is often the result of nephropathy. Blood pressure measurement at every routine visit is recommended [90]. In most adult patients with diabetes, a fasting lipid profile at least once a year is recommended [90]. Low-risk lipid values (LDL cholesterol $<100 \mathrm{mg} / \mathrm{dL}$, HDL $>50 \mathrm{mg} / \mathrm{dL}$, triglycerides $<150 \mathrm{mg} / \mathrm{dL}$ ) provided, assessment may be repeated biannually [90].

In type 1 diabetic patients with diabetes duration $\geq 5$ years, the screening for nephropathy should include an annual assessment of urine albumin excretion [90]. Irrespective of the degree of urine albumin excretion, in all adults with diabetes serum creatinine should be measured at least annually [90]. The creatinine value is useful for estimation of glomerular filtration rate (GFR) [90]. In children and adolescent patients, annual screening both for nephropathy and retinopathy is recommended to 
start at age 11 years in case of 2 years diabetes duration and at age 9 years with 5 years duration, respectively [91].

Screening for signs and symptoms of CV autonomic neuropathy should be started 5 years after the diagnosis of type 1 diabetes $[16,90]$. CV reflex tests are the gold standard in clinical autonomic testing. The most widely used tests assessing cardiac parasympathetic function are based on the time-domain heart rate response to deep breathing, Valsalva maneuver, and postural change. Age is a strong modulator of these tests and needs to be considered when interpreting the results. CV sympathetic function is assessed by measuring the blood pressure response to standing [92].

PWA may contribute to assessment of $\mathrm{CV}$ risk in patients with type 1 diabetes [78]. In a study, greater augmentation pressure was independently associated with prevalent $\mathrm{CAD}$ and estimated myocardial perfusion with low ABI $(<0.90)$ [78]. Screening patients for silent myocardial ischemia is controversial but seems reasonable in very high risk patients, in particular in those with long duration of diabetes and proteinuria or evidence of peripheral artery disease, and in those who wish to start a vigorous exercise program. Measurement of CAC score may be suggested as a first line investigation, leading to a stress test if the score is higher than $400[93,94]$.

\section{Treatment}

\section{Gycemic control}

Intensive insulin therapy has been strongly demonstrated to reduce the onset as well as progression of all diabetesrelated microvascular complications [58,60,95-98]. The Diabetes Control and Complications Trial (DCCT)/ Epidemiology of Diabetes Interventions and Complications (EDIC) study found in approximately 1,200 patients with type 1 diabetes a relative CVD risk reduction of $40 \%$, adjusted for other risk factors including albuminuria, when comparing intensive vs. standard treatment (mean $\mathrm{HbAlc}$ $7.4 \%$ vs. 9.1\%) for 11 years [58]. In adolescent patients, intensive treatment (HbA1c 8.1\%) as compared to conventional treatment (HbA1c 9.8\%) has been shown to reduce the risk and progression of background retinopathy by $53 \%$, clinical neuropathy by $60 \%$, and microalbuminuria by $54 \%$ [60]. A prolonged effect of early intensive approaches was also seen in a four year follow-up of intensively treated adolescent type 1 diabetic patients [99].

Several studies confirmed the association between poor glycemic control and an increasing risk for nephropathy [100-102], retinopathy $[95,103,104]$, and neuropathy [105-109]. A large proportion of patients, however, fails to achieve glycemic targets [110-112].

\section{GLP-1 based treatment as an add-on to insulin}

Due to their action on insulin secretion and glucose regulation, glucagone-like peptide (GLP)-1 based treatment approaches have been established in the treatment of type 2 diabetes. Based on in vitro and animal studies, GLP-1 based drugs have been assumed to additionally may be effective in preserving and even expanding the beta cell mass [113]. In a small study on 15 patients with newly detected type 1 diabetes, the addition of exenatide at onset of diabetes has been shown to decrease insulin requirement [113]. Three groups of patients have been formed: group1 (insulin alone), group 2 (insulin and exenatide), and group 3 (insulin and sitagliptin).

After one year, a decrease in insulin requirement of $16.7 \pm 12.5,39.8 \pm 17.2,21.2 \pm 9.6$ units in groups 1,2 and 3 respectively $(P=0.0431)$ was detected. A mean stimulated c peptide secretion of $0.34 \pm 0.12,0.45 \pm 0.34$, $0.44 \pm 0.5 \mathrm{ng} / \mathrm{mL}$ was found $(\mathrm{P}=0.8656)$. The maximum percentage preservation in c peptide was observed in the patients of group 2 [113]. Of relevance is the evidence that GLP-1 can protect type 1 diabetic patients by both acute hyperglycemia or hypoglycaemia induced endothelial dysfunction, oxidative stress and inflammation [114].

\section{Approaches beyond glycemic control}

In contrast to DCCT/EDIC, some trials did not confirm the association between glycemic control and CVD risk [115-117]. Discrepancies are suggested to be based on differences between the study populations [118]. With view on prevention and treatment of $C A D$, it is recommended to focus not only on glycemic control [118]. Traditional risk factors such as albuminuria, the metabolic syndrome, and inflammatory markers should also be addressed [118].

International guidelines recommend lowering blood pressure in diabetes to prevent macro- and micro-vascular outcomes. However, most evidence from randomized clinical trials refers to type 2 diabetes. A goal of blood pressure $<130$ and $<80 \mathrm{mmHg}$ has been recommended $[90,119]$. The most recent recommendations of the American Diabetes Association (ADA) set a blood pressure goal of $<140 /<80 \mathrm{mmHg}$ for persons with diabetes and hypertension; lower targets (such as $<130 \mathrm{~mm} \mathrm{Hg}$ ) may be appropriate in patients if the specific target can be achieved without an additional burden of treatment [90].

Pharmacological therapy in people with diabetes and hypertension should be with a regimen that includes either an angiotensin converting enzyme (ACE)-inhibitor or an angiotensin-receptor blocker (ARB) [90]. Generally, two or more drugs are required to achieve blood pressure targets in diabetics. Preferred combinations are either ACE-inhibitors or ARBs (not together) with a calciumchannel blocker or a diuretic. For the latter, both thiazide [90] and, more recently, thiazide-like diuretics [120] are recommended.

However, more recent appraisal of the evidence indicates lack of evidence to support systolic blood pressure 
targets $<130 \mathrm{mmHg}$ and suggests optimal diastolic blood pressure between 80 and $85 \mathrm{mmHg}$ [72].

In studies among patients with diabetes, regular physical activity has been demonstrated to reduce CVD-related and total mortality [11]. Early treatment of hypertension has been reported to prevent end-stage kidney disease in patients with type 1 diabetes [121]. Angiotensin-converting enzyme (ACE) inhibitors have been demonstrated to be effective and safe in in reducing microalbuminuria [122]. In adolescent patients with persistent microalbuminuria, the use of ACE inhibitors $[91,100,123]$ or angiotensin II receptor blockers [91] is recommended to prevent the progression to macroalbuminuria. Furthermore, in order to reduce progression of microalbuminuria, cessation of smoking is strongly recommended $[117,124,125]$.

Lifestyle modification is recommended for the improvement of lipid profile. In diabetic patients with overt CVD, statins should be added irrespective of lipid levels [90]. Statin therapy is also recommended in diabetic patients without CVD aged $>40$ years and $\geq 1$ other CVD risk factor (family history of CVD, hypertension, smoking, dyslipidemia, albuminuria) [90]. In patients with lower CV risk, statin therapy should be considered if LDL cholesterol remains above $100 \mathrm{mg} / \mathrm{dL}$ [90]. In diabetic patients without overt CVD, the goal for LDL cholesterol is $100 \mathrm{mg} / \mathrm{dL}$ ( $2.6 \mathrm{mmol} / \mathrm{L})$. In patients with overt CVD, a LDL cholesterol goal of $70 \mathrm{mg} / \mathrm{dL}(1.8 \mathrm{mmol} / \mathrm{L})$, using a high dose of a statin, may be considered [90].

\section{Discussion / Outlook}

Despite of a remarkable improvement in life expectancy, type 1 diabetic patients are confronted with an increased risk of CV mortality, an evidence often underrecognized. Further improvement may base on consequent risk assessment and management of risk factors. Estimation of CV risk including the role of surrogate markers deserves more attention in the future. Currently, optimized glycemic control is considered to be the most promising approach. Recent research on a small group of patients suggests the addition of exenatide at onset of diabetes to decrease insulin requirement. These results, however, need to be confirmed by further investigation on larger groups of patients.

\section{Competing interests}

The authors declare that they have no competing interests.

\section{Authors' contributions}

All authors contributed to conception and design, drafting the article, revising the article critically, final approval of the version to be published.

\section{Author details}

${ }^{1}$ Forschergruppe Diabetes e.V., Helmholtz Center Munich, Ingolstaedter Landstrasse 1, 85764 Munich-Neuherberg, Germany. ${ }^{2}$ University of Warwick, Warwick, UK. ${ }^{3}$ Department of Cardiovascular and Metabolic Diseases, Gruppo Multimedica, Sesto San Giovanni, Milan, Italy. ${ }^{4}$ Service d'Endocrinologie-Diabétologie-Nutrition, Hôpital Jean Verdier, Bondy Cedex, France. Insititut d'Investigacions Biomèdiques August Pi i Sunyer (IDIBAPS) and Centro de Investigación Biomédica en Red de Diabetes y
Enfermedades Metabólicas Asociadas (CIBERDEM), Hospital Clínic Barcelona, Barcelona, Spain.

Received: 17 August 2013 Accepted: 8 October 2013

Published: 28 October 2013

\section{References}

1. Preis SR, Hwang SJ, Coady S, et al: Trends in all-cause and cardiovascular disease mortality among women and men with and without diabetes mellitus in the Framingham Heart Study, 1950 to 2005. Circulation 2009, 119:1728-1735.

2. Nishimura R, LaPorte RE, Dorman JS, et al: Mortality trends in type 1 diabetes. The Allegheny County (Pennsylvania) Registry 1965-1999. Diabetes Care 2001, 24:823-827.

3. Miller RG, Secrest AM, Sharma RK, Songer TJ, Orchard TJ: Improvements in the life expectancy of type 1 diabetes: the Pittsburgh Epidemiology of Diabetes Complications study cohort. Diabetes 2012, 61:2987-2992.

4. Schnell O, Standl E: Diabetes and cardiovascular disease. Current status of trials. Clin Res Cardiol Suppl 2010, (5):27-34.

5. Koivisto VA, Stevens LK, Mattock M, et al: Cardiovascular disease and its risk factors in IDDM in Europe, EURODIAB IDDM Complications Study Group. Diabetes Care 1996, 19:689-697.

6. Juutilainen A, Lehto S, Ronnemaa T, Pyorala K, Laakso M: Similarity of the impact of type 1 and type 2 diabetes on cardiovascular mortality in middle-aged subjects. Diabetes Care 2008, 31:714-719.

7. Standl E, Balletshofer B, Dahl B, et al: Predictors of 10-year macrovascular and overall mortality in patients with NIDDM: the Munich General Practitioner Project. Diabetologia 1996, 39:1540-1545.

8. Shankar A, Klein R, Klein BE, Moss SE: Association between glycosylated hemoglobin level and cardiovascular and all-cause mortality in type 1 diabetes. Am J Epidemiol 2007, 166:393-402.

9. Morimoto A, Onda $Y$, Nishimura R, et al: Cause-specific mortality trends in a nationwide population-based cohort of childhood-onset type 1 diabetes in Japan during 35 years of follow-up: the DERI Mortality Study. Diabetologia 2013, 56:2171-2175.

10. Constantino Ml, Molyneaux L, Limacher-Gisler F, et al: Long-Term Complications and Mortality in Young-Onset Diabetes: Type 2 diabetes is more hazardous and lethal than type 1 diabetes. Diabetes Care 2013.

11. Ryden L, Standl E, Bartnik M, et al: Guidelines on diabetes, pre-diabetes, and cardiovascular diseases: executive summary. The Task Force on Diabetes and Cardiovascular Diseases of the European Society of Cardiology (ESC) and of the European Association for the Study of Diabetes (EASD). Eur Heart J 2007, 28:88-136.

12. Ceriello A: New insights on oxidative stress and diabetic complications may lead to a "causal" antioxidant therapy. Diabetes Care 2003, 26:1589-1596.

13. Ceriello A: Postprandial hyperglycemia and diabetes complications: is it time to treat? Diabetes 2005, 54:1-7.

14. Desouza CV, Bolli GB, Fonseca V: Hypoglycemia, diabetes, and cardiovascular events. Diabetes Care 2010, 33:1389-1394.

15. Alzahrani SH, Ajjan RA: Coagulation and fibrinolysis in diabetes. Diab Vasc Dis Res 2010, 7:260-273.

16. Spallone V, Ziegler D, Freeman $R$, et al: Cardiovascular autonomic neuropathy in diabetes: clinical impact, assessment, diagnosis, and management. Diabetes Metab Res Rev 2011. doi: 10.1002/dmrr.1239.

17. Witte DR, Tesfaye S, Chaturvedi N, et al: Risk factors for cardiac autonomic neuropathy in type 1 diabetes mellitus. Diabetologia 2005, 48:164-171.

18. The DCCT Research Group: The effect of intensive diabetes therapy on measures of autonomic nervous system function in the Diabetes Control and Complications Trial (DCCT). Diabetologia 1998, 41:416-423.

19. Pop-Busui $R$, Low PA, Waberski BH, et al: Effects of prior intensive insulin therapy on cardiac autonomic nervous system function in type 1 diabetes mellitus: the Diabetes Control and Complications Trial/Epidemiology of Diabetes Interventions and Complications study (DCCT/EDIC). Circulation 2009, 119:2886-2893.

20. Astrup AS, Tarnow L, Rossing P, et al: Cardiac autonomic neuropathy predicts cardiovascular morbidity and mortality in type 1 diabetic patients with diabetic nephropathy. Diabetes Care 2006, 29:334-339.

21. Ayad F, Belhadj M, Paries J, Attali JR, Valensi P: Association between cardiac autonomic neuropathy and hypertension and its potential influence on diabetic complications. Diabet Med 2010, 27:804-811. 
22. Prince $\mathrm{CT}$, Secrest $\mathrm{AM}$, Mackey $\mathrm{RH}$, et al: Cardiovascular autonomic neuropathy, HDL cholesterol, and smoking correlate with arterial stiffness markers determined 18 years later in type 1 diabetes. Diabetes Care 2010, 33:652-657.

23. Standl E, Schnell O: A new look at the heart in diabetes mellitus: from ailing to failing. Diabetologia 2000, 43:1455-1469.

24. Schnell O: Cardiac sympathetic innervation and blood flow regulation of the diabetic heart. Diabetes Metab Res Rev 2001, 17:243-245.

25. Schnell O, Kirsch CM, Stemplinger J, Haslbeck M, Standl E: Scintigraphic evidence for cardiac sympathetic dysinnervation in long-term IDDM patients with and without ECG-based autonomic neuropathy. Diabetologia 1995, 38:1345-1352.

26. Hattori N, Tamaki N, Hayashi T, et al: Regional abnormality of iodine-123-MIBG in diabetic hearts. J Nucl Med 1996, 37:1985-1990.

27. Schnell O, Muhr D, Weiss M, et al: Reduced myocardial 123I-metaiodobenzylguanidine uptake in newly diagnosed IDDM patients. Diabetes 1996, 45:801-805.

28. Munch G, Ziegler S, Nguyen N, et al: Scintigraphic evaluation of cardiac autonomic innervation. J Nucl Cardiol 1996, 3:265-277.

29. Schnell O, Muhr D, Dresel S, et al: Partial restoration of scintigraphically assessed cardiac sympathetic denervation in newly diagnosed patients with insulin-dependent (type 1) diabetes mellitus at one-year follow-up. Diabet Med 1997, 14:57-62.

30. Meyer C, Schwaiger M: Myocardial blood flow and glucose metabolism in diabetes mellitus. Am J Cardio/ 1997, 80:94A-101A.

31. Stevens MJ, Dayanikli F, Raffel DM, et al: Scintigraphic assessment of regionalized defects in myocardial sympathetic innervation and blood flow regulation in diabetic patients with autonomic neuropathy. J Am Coll Cardiol 1998, 31:1575-1584.

32. Vom-Dahl J, Herman WH, Hicks RJ, et al: Myocardial glucose uptake in patients with insulin-dependent diabetes mellitus assessed quantitatively by dynamic positron emission tomography. Circulation 1993, 88:395-404.

33. Hattori N, Tamaki N, Kudoh T, et al: Abnormality of myocardial oxidative metabolism in noninsulin-dependent diabetes mellitus. J Nucl Med 1998 39:1835-1840

34. Pop-Busui R: What do we know and we do not know about cardiovascular autonomic neuropathy in diabetes. J Cardiovasc Trans/ Res 2012, 5:463-478.

35. Pop-Busui R, Kirkwood I, Schmid H, et al: Sympathetic dysfunction in type 1 diabetes: association with impaired myocardial blood flow reserve and diastolic dysfunction. J Am Coll Cardiol 2004, 44:2368-2374.

36. Pfeifer MA, Schumer MP: Clinical trials of diabetic neuropathy: past, present, and future. Diabetes 1995, 44:1355-1361.

37. Allman KC, Stevens MJ, Wieland DM, et al: Noninvasive assessment of cardiac diabetic neuropathy by carbon-11 hydroxyephedrine and positron emission tomography. J Am Coll Cardiol 1993, 22:1425-1432.

38. Stevens MJ, Raffel DM, Allman KC, et al: Cardiac sympathetic dysinnervation in diabetes: implications for enhanced cardiovascular risk. Circulation 1998, 98:961-968.

39. Schnell O, Muhr D, Dresel $S$, et al: Autoantibodies against sympathetic ganglia and evidence of cardiac sympathetic dysinnervation in newly diagnosed and long-term IDDM patients. Diabetologia 1996, 39:970-975.

40. Muhr D, Mollenhauer U, Ziegler AG, et al: Autoantibodies to sympathetic ganglia, GAD, or tyrosine phosphatase in long-term IDDM with and without ECG-based cardiac autonomic neuropathy. Diabetes Care 1997, 20:1009-1012.

41. Muhr-Becker D, Ziegler AG, Druschky A, et al: Evidence for specific autoimmunity against sympathetic and parasympathetic nervous tissues in Type 1 diabetes mellitus and the relation to cardiac autonomic dysfunction. Diabet Med 1998, 15:467-472.

42. Ejskjaer N, Arif S, Dodds W, et al: Prevalence of autoantibodies to autonomic nervous tissue structures in Type 1 diabetes mellitus. Diabet Med 1999, 16:544-549.

43. Rabinowe SL, Brown FM, Watts M, Kadrofske MM, Vinik Al: Anti-sympathetic ganglia antibodies and postural blood pressure in IDDM subjects of varying duration and patients at high risk of developing IDDM. Diabetes Care 1989, 12:1-6.

44. Sundkvist $G$, Lind P, Bergstrom B, Lilja B, Rabinowe SL: Autonomic nerve antibodies and autonomic nerve function in type 1 and type 2 diabetic patients. J Intern Med 1991, 229:505-510.

45. Zanone MM, Peakman M, Purewal T, Watkins PJ, Vergani D: Autoantibodies to nervous tissue structures are associated with autonomic neuropathy in type 1 (insulin-dependent) diabetes mellitus. Diabetologia 1993, 36:564-569.
46. Frier BM, Schernthaner G, Heller SR: Hypoglycemia and cardiovascular risks. Diabetes Care 2011, 34(Suppl 2):S132-S137.

47. Wright RJ, Frier BM: Vascular disease and diabetes: is hypoglycaemia an aggravating factor? Diabetes Metab Res Rev 2008, 24:353-363.

48. Sommerfield AJ, Wilkinson IB, Webb DJ, Frier BM: Vessel wall stiffness in type 1 diabetes and the central hemodynamic effects of acute hypoglycemia. Am J Physiol Endocrinol Metab 2007, 293:E1274-E1279.

49. Robinson RT, Harris ND, Ireland RH, et al: Mechanisms of abnormal cardiac repolarization during insulin-induced hypoglycemia. Diabetes 2003, 52:1469-1474.

50. Koivikko ML, Karsikas M, Salmela PI, et al: Effects of controlled hypoglycaemia on cardiac repolarisation in patients with type 1 diabetes. Diabetologia 2008, 51:426-435

51. Tattersall RB, Gill GV: Unexplained deaths of type 1 diabetic patients. Diabet Med 1991, 8:49-58.

52. Campbell I: Dead in bed syndrome: a new manifestation of nocturnal hypoglycaemia? Diabet Med 1991, 8:3-4.

53. Sartor G, Dahlquist G: Short-term mortality in childhood onset insulin-dependent diabetes mellitus: a high frequency of unexpected deaths in bed. Diabet Med 1995, 12:607-611.

54. Dahlquist $\mathrm{G}$, Kallen B: Mortality in childhood-onset type 1 diabetes: a population-based study. Diabetes Care 2005, 28:2384-2387.

55. Skrivarhaug T, Bangstad HJ, Stene LC, et al: Long-term mortality in a nationwide cohort of childhood-onset type 1 diabetic patients in Norway. Diabetologia 2006, 49:298-305.

56. Tu E, Twigg SM, Duflou J, Semsarian C: Causes of death in young Australians with type 1 diabetes: a review of coronial postmortem examinations. Med J Aust 2008, 188:699-702.

57. Barkai L, Gurieva I, Stirban A, et al: Microvascular complications in children and adolescents with type 1 diabetes. Diabetes Metab Heart 2012, 21:309-315.

58. Nathan DM, Cleary PA, Backlund JY, et al: Intensive diabetes treatment and cardiovascular disease in patients with type 1 diabetes. N Engl J Med 2005, 353:2643-2653.

59. Orchard TJ, Olson JC, Erbey JR, et al: Insulin resistance-related factors, but not glycemia, predict coronary artery disease in type 1 diabetes: 10-year follow-up data from the Pittsburgh Epidemiology of Diabetes Complications Study. Diabetes Care 2003, 26:1374-1379.

60. The DCCT Research Group: The effect of intensive treatment of diabetes on the development and progression of long-term complications in insulin-dependent diabetes mellitus. The Diabetes Control and Complications Trial Research Group. N Engl J Med 1993, 329:977-986.

61. Sustained effect of intensive treatment of type 1 diabetes mellitus on development and progression of diabetic nephropathy: the Epidemiology of Diabetes Interventions and Complications (EDIC) study. JAMA 2003, 290:2159-2167.

62. Monti MC, Lonsdale JT, Montomoli C, et al: Familial risk factors for microvascular complications and differential male-female risk in a large cohort of American families with type 1 diabetes. J Clin Endocrinol Metab 2007, 92:4650-4655.

63. Conway $B$, Costacou T, Orchard T: Is glycaemia or insulin dose the stronger risk factor for coronary artery disease in type 1 diabetes? Diab Vasc Dis Res 2009, 6:223-230.

64. Dorchy H, Claes C, Verougstraete C: Risk factors of developing proliferative retinopathy in type 1 diabetic patients: role of BMI. Diabetes Care 2002, 25:798-799.

65. De Block CE, De Leeuw IH, Van Gaal LF: Impact of overweight on chronic microvascular complications in type 1 diabetic patients. Diabetes Care 2005, 28:1649-1655.

66. Stone ML, Craig ME, Chan AK, et al: Natural history and risk factors for microalbuminuria in adolescents with type 1 diabetes: a longitudinal study. Diabetes Care 2006, 29:2072-2077.

67. Tesfaye S, Stevens LK, Stephenson JM, et al: Prevalence of diabetic peripheral neuropathy and its relation to glycaemic control and potential risk factors: the EURODIAB IDDM Complications Study. Diabetologia 1996, 39:1377-1384.

68. Chase HP, Garg SK, Marshall G, et al: Cigarette smoking increases the risk of albuminuria among subjects with type I diabetes. JAMA 1991, 265:614-617.

69. Mohamed Q, Gillies MC, Wong TY: Management of diabetic retinopathy: a systematic review. JAMA 2007, 298:902-916. 
70. Tuomilehto J, Borch-Johnsen K, Molarius A, et al: Incidence of cardiovascular disease in Type 1 (insulin-dependent) diabetic subjects with and without diabetic nephropathy in Finland. Diabetologia 1998, 41:784-790.

71. Turkbey EB, Backlund JY, Genuth S, et al: Myocardial structure, function, and scar in patients with type 1 diabetes mellitus. Circulation 2011, 124:1737-1746.

72. Mancia G, Fagard R, Narkiewicz K, et al: 2013 ESH/ESC Guidelines for the management of arterial hypertension: The Task Force for the management of arterial hypertension of the European Society of Hypertension (ESH) and of the European Society of Cardiology (ESC). Eur Heart J 2013. Epub ahead of print.

73. Viberti GC, Keen H, Wiseman MJ: Raised arterial pressure in parents of proteinuric insulin dependent diabetics. Br Med J (Clin Res Ed) 1987, 295:515-517.

74. Krolewski AS, Canessa M, Warram JH, et al: Predisposition to hypertension and susceptibility to renal disease in insulin-dependent diabetes mellitus. N Engl J Med 1988, 318:140-145.

75. Lurbe E, Redon J, Kesani A, et al: Increase in nocturnal blood pressure and progression to microalbuminuria in type 1 diabetes. N Engl J Med 2002, 347:797-805.

76. de Boer IH, Kestenbaum B, Rue TC, et al: Insulin therapy, hyperglycemia, and hypertension in type 1 diabetes mellitus. Arch Intern Med 2008, 168:1867-1873.

77. Giuffrida FM, Guedes AD, Rocco ER, et al: Heterogeneous behavior of lipids according to $\mathrm{HbA} 1 \mathrm{c}$ levels undermines the plausibility of metabolic syndrome in type 1 diabetes: data from a nationwide multicenter survey. Cardiovasc Diabetol 2012, 11:156.

78. Prince $\mathrm{CT}$, Secrest $\mathrm{AM}$, Mackey $\mathrm{RH}$, et al: Pulse wave analysis and prevalent cardiovascular disease in type 1 diabetes. Atherosclerosis 2010, 213:469-474.

79. Turkbey EB, Redheuil A, Backlund JY, et al: Aortic Distensibility in Type 1 Diabetes. Diabetes Care 2013. Epub ahead of print.

80. Genuth S, Backlund JY, Bayless M, et al: Effects of Prior Intensive versus Conventional Therapy and History of Glycemia on Cardiac Function in Type 1 Diabetes in the DCCT/EDIC. Diabetes 2013. Epub ahead of print.

81. Nathan DM, Lachin J, Cleary P, et al: Intensive diabetes therapy and carotid intima-media thickness in type 1 diabetes mellitus. N Engl J Med 2003, 348:2294-2303.

82. Olson JC, Edmundowicz D, Becker DJ, Kuller LH, Orchard TJ: Coronary calcium in adults with type 1 diabetes: a stronger correlate of clinical coronary artery disease in men than in women. Diabetes 2000, 49:1571-1578.

83. Snell-Bergeon JK, Hokanson JE, Jensen L, et al: Progression of coronary artery calcification in type 1 diabetes: the importance of glycemic control. Diabetes Care 2003, 26:2923-2928.

84. Thilo C, Standl E, Knez A, et al: Coronary calcification in long-term type 1 diabetic patients - a study with multi slice spiral computed tomography. Exp Clin Endocrinol Diabetes 2004, 112:561-565

85. Rathsman B, Rosfors S, Sjoholm A, Nystrom T: Early signs of atherosclerosis are associated with insulin resistance in non-obese adolescent and young adults with type 1 diabetes. Cardiovasc Diabetol 2012, 11:145.

86. Dalla Pozza R, Beyerlein A, Thilmany C, et al: The effect of cardiovascular risk factors on the longitudinal evolution of the carotid intima medial thickness in children with type 1 diabetes mellitus. Cardiovasc Diabetol 2011, 10:53.

87. Turek SJ, Hastings SM, Sun JK, King GL, Keenan HA: Sexual Dysfunction as a Marker of Cardiovascular Disease in Males With 50 or More Years of Type 1 Diabetes. Diabetes Care 2013, 36(10):3222-3226.

88. Pratte $K A$, Baron $A E$, Ogden $L G$, et al: Plasminogen activator inhibitor- 1 is associated with coronary artery calcium in Type 1 diabetes. J Diabetes Complications 2009, 23:387-393.

89. Bosnyak Z, Forrest KY, Maser RE, Becker D, Orchard TJ: Do plasminogen activator inhibitor (PAI-1) or tissue plasminogen activator PAl-1 complexes predict complications in Type 1 diabetes: the Pittsburgh Epidemiology of Diabetes Complications Study. Diabet Med 2003, 20:147-151.

90. American Diabetes Association (ADA): Standards of medical care in diabetes - 2013. Diabetes Care 2013, 36:S11-S66.

91. Donaghue KC, Chiarelli F, Trotta D, Allgrove J, Dahl-Jorgensen K: Microvascular and macrovascular complications associated with diabetes in children and adolescents. Pediatr Diabetes 2009, 10(Suppl 12):195-203.

92. Tesfaye S, Boulton AJ, Dyck PJ, et al: Diabetic neuropathies: update on definitions, diagnostic criteria, estimation of severity, and treatments. Diabetes Care 2010, 33:2285-2293.
93. Geluk CA, Dikkers R, Kors JA, et al: Measurement of coronary calcium scores or exercise testing as initial screening tool in asymptomatic subjects with ST-T changes on the resting ECG: an evaluation study. BMC Cardiovasc Disord 2007, 7:19.

94. Budoff MJ, Gul KM: Expert review on coronary calcium. Vasc Health Risk Manag 2008, 4:315-324.

95. Donaghue KC, Fairchild JM, Craig ME, et al: Do all prepubertal years of diabetes duration contribute equally to diabetes complications? Diabetes Care 2003, 26:1224-1229.

96. Effect of intensive diabetes treatment on the development and progression of long-term complications in adolescents with insulin-dependent diabetes mellitus: Diabetes Control and Complications Trial. Diabetes Control and Complications Trial Research Group. J Pediatr 1994, 125:177-188.

97. UK Prospective Diabetes Study (UKPDS) Group: Intensive blood-glucose control with sulphonylureas or insulin compared with conventional treatment and risk of complications in patients with type 2 diabetes (UKPDS 33). UK Prospective Diabetes Study (UKPDS) Group. Lancet 1998, 352:837-853.

98. Shichiri M, Kishikawa H, Ohkubo Y, Wake N: Long-term results of the Kumamoto Study on optimal diabetes control in type 2 diabetic patients. Diabetes Care 2000, 23(Suppl 2):B21-B29.

99. Retinopathy and nephropathy in patients with type 1 diabetes fou years after a trial of intensive therapy. The Diabetes Control and Complications Trial/Epidemiology of Diabetes Interventions and Complications Research Group. N Engl J Med 2000, 342:381-389.

100. Salardi S, Balsamo C, Zucchini S, et al: High rate of regression from micro-macroalbuminuria to normoalbuminuria in children and adolescents with type 1 diabetes treated or not with enalapril: the influence of HDL cholesterol. Diabetes Care 2011, 34:424-429.

101. Amin R, Widmer B, Prevost AT, et al: Risk of microalbuminuria and progression to macroalbuminuria in a cohort with childhood onset type 1 diabetes: prospective observational study. BMJ 2008, 336:697-701.

102. Gorman D, Sochett E, Daneman D: The natural history of microalbuminuria in adolescents with type 1 diabetes. J Pediatr 1999, 134:333-337.

103. Klein R, Klein BE, Moss SE, Cruickshanks KJ: The Wisconsin Epidemiologic Study of Diabetic Retinopathy: XVII. The 14-year incidence and progression of diabetic retinopathy and associated risk factors in type 1 diabetes. Ophthalmology 1998, 105:1801-1815.

104. Kubin M, Tossavainen $P$, Hannula $V$, et al: Prevalence of retinopathy in Finnish children and adolescents with type 1 diabetes: a cross-sectional population-based retrospective study. Arch Dis Child 2011, 96:963-968.

105. Barkai L, Kempler P, Vamosi I, et al: Peripheral sensory nerve dysfunction in children and adolescents with type 1 diabetes mellitus. Diabet Med 1998, 15:228-233.

106. Hyllienmark L, Brismar T, Ludvigsson J: Subclinical nerve dysfunction in children and adolescents with IDDM. Diabetologia 1995, 38:685-692.

107. Lee SS, Han HS, Kim H: A 5-yr follow-up nerve conduction study for the detection of subclinical diabetic neuropathy in children with newly diagnosed insulin-dependent diabetes mellitus. Pediatr Diabetes 2010, 11:521-528.

108. Riihimaa PH, Suominen $\mathrm{K}$, Tolonen $U$, et al: Peripheral nerve function is increasingly impaired during puberty in adolescents with type 1 diabetes. Diabetes Care 2001, 24:1087-1092.

109. Solders $G$, Thalme B, Aguirre-Aquino $M$, et al: Nerve conduction and autonomic nerve function in diabetic children. A 10-year follow-up study. Acta Paediatr 1997, 86:361-366

110. Craig ME, Handelsman P, Donaghue KC, et al: Predictors of glycaemic control and hypoglycaemia in children and adolescents with type 1 diabetes from NSW and the ACT. Med J Aust 2002, 177:235-238.

111. Vanelli M, Chiarelli F, Chiari G, Tumini S: Relationship between metabolic control and quality of life in adolescents with type 1 diabetes. Report from two Italian centres for the management of diabetes in childhood. Acta Biomed 2003, 74(Suppl 1):13-17.

112. Holl RW, Swift PG, Mortensen $H B$, et al: Insulin injection regimens and metabolic control in an international survey of adolescents with type 1 diabetes over 3 years: results from the Hvidore study group. Eur J Pediatr 2003, 162:22-29.

113. Hari Kumar KV, Shaikh A, Prusty P: Addition of exenatide or sitagliptin to insulin in new onset type 1 diabetes: A randomized, open label study. Diabetes Res Clin Pract 2013. doi: 10.1016/j.diabres.2013.1001.1020.

114. Ceriello A, Novials A, Ortega E, et al: Glucagon-Like Peptide 1 Reduces Endothelial Dysfunction, Inflammation, and Oxidative Stress Induced by 
Both Hyperglycemia and Hypoglycemia in Type 1 Diabetes. Diabetes Care 2013, 36(8):2346-2350.

115. Klein R, Klein BE, Moss SE: The Wisconsin epidemiological study of diabetic retinopathy: a review. Diabetes Metab Rev 1989, 5:559-570.

116. van Hecke MV, Dekker JM, Stehouwer CD, et al: Diabetic retinopathy is associated with mortality and cardiovascular disease incidence: the EURODIAB prospective complications study. Diabetes Care 2005, 28:1383-1389.

117. Rossing P, Hougaard P, Parving HH: Risk factors for development of incipient and overt diabetic nephropathy in type 1 diabetic patients: a 10-year prospective observational study. Diabetes Care 2002, 25:859-864.

118. Wajchenberg BL, Feitosa AC, Rassi N, Lerario AC, Betti RT: Glycemia and cardiovascular disease in type 1 diabetes mellitus. Endocr Pract 2008, 14:912-923

119. American Diabetes Association: Hypertension Management in Adults With Diabetes. Diabetes Care 2004, 27:565-s67.

120. NICE. Hypertension: The clinical management of primary hypertension in adults. NICE Clinical Guideline 127. 2011. Available at http://publications.nice. org.uk/hypertension-cg127 [last accessed: 02-07-2013]. 2011.

121. Rossing P, Hougaard P, Borch-Johnsen K, Parving HH: Predictors of mortality in insulin dependent diabetes: 10 year observational follow up study. BMJ 1996, 313:779-784.

122. Cook J, Daneman D, Spino M, et al: Angiotensin converting enzyme inhibitor therapy to decrease microalbuminuria in normotensive children with insulin-dependent diabetes mellitus. J Pediatr 1990, 117:39-45.

123. : The fourth report on the diagnosis, evaluation, and treatment of high blood pressure in children and adolescents. Pediatrics 2004, 114:555-576.

124. Couper JJ, Staples AJ, Cocciolone R, et al: Relationship of smoking and albuminuria in children with insulin-dependent diabetes. Diabet Med 1994, 11:666-669.

125. Astrup AS, Tarnow L, Rossing P, et al: Improved prognosis in type 1 diabetic patients with nephropathy: a prospective follow-up study. Kidney Int 2005, 68:1250-1257.

doi:10.1186/1475-2840-12-156

Cite this article as: Schnell et al:: Type 1 diabetes and cardiovascular disease. Cardiovascular Diabetology 2013 12:156.

\section{Submit your next manuscript to BioMed Central and take full advantage of:}

- Convenient online submission

- Thorough peer review

- No space constraints or color figure charges

- Immediate publication on acceptance

- Inclusion in PubMed, CAS, Scopus and Google Scholar

- Research which is freely available for redistribution 